\title{
ORIGINAL ARTICLE Toll-like receptor 4 region genetic variants are associated with susceptibility to melioidosis
}

\author{
TE West ${ }^{1,2}$, W Chierakul ${ }^{3,4}$, N Chantratita ${ }^{3,5}$, D Limmathurotsakull,6, V Wuthiekanun ${ }^{3}$, MJ Emond ${ }^{7}$, \\ TR Hawn ${ }^{8}$, SJ Peacock ${ }^{9}$ and SJ Skerrett ${ }^{1}$ \\ ${ }^{1}$ Division of Pulmonary \& Critical Care Medicine, Department of Medicine, Harborview Medical Center, University of Washington, \\ Seattle, WA, USA; ${ }^{2}$ International Respiratory and Severe Illness Center, University of Washington, Seattle, WA, USA; ${ }^{3}$ Mahidol-Oxford \\ Tropical Medicine Research Unit, Faculty of Tropical Medicine, Mahidol University, Bangkok, Thailand; ${ }^{4}$ Department of Clinical Tropical \\ Medicine, Faculty of Tropical Medicine, Mahidol University, Bangkok, Thailand; ${ }^{5}$ Department of Microbiology and Immunology, Faculty \\ of Tropical Medicine, Mahidol University, Bangkok, Thailand; ' ${ }^{2}$ epartment of Tropical Hygiene, Faculty of Tropical Medicine, Mahidol \\ University, Bangkok, Thailand; ' ${ }^{7}$ epartment of Biostatistics, University of Washington, Seattle, WA, USA; ${ }^{8}$ Division of Allergy $\mathcal{E}$ \\ Infectious Diseases, Department of Medicine, University of Washington, Seattle, WA, USA and 'Department of Medicine, Addenbrooke's \\ Hospital, University of Cambridge, Cambridge, UK
}

\begin{abstract}
Melioidosis is a tropical infection caused by the Gram-negative soil saprophyte Burkholderia pseudomallei. Despite broad exposure of northeastern Thais, disease develops in only a small proportion of individuals. Although diabetes is a risk factor, the mechanisms of host susceptibility to melioidosis are still poorly understood. We postulated that Toll-like receptors (TLRs) regulate host susceptibility to disease, and that genetic variation in TLRs is associated with melioidosis. We analyzed the frequency of eight previously described TLR pathway polymorphisms in 490 cases compared with 950 non-hospitalized controls or 458 hospitalized controls. Based on these results, we then analyzed the frequency of additional TLR4 or TLR6-1-10 region polymorphisms in cases and controls. We found that the $T L R 4_{1196 C>T}$ variant was associated with protection from melioidosis when compared with non-hospitalized controls. The TLR1 $1_{742 A>G}$ and TLR1 $1_{-7202 A>G}$ variants were associated with melioidosis when compared with hospitalized controls. In further analyses, we found that two additional TLR4 region polymorphisms were associated with disease. In diabetics, three other TLR6-1-10 region polymorphisms were associated with disease when compared with hospitalized controls. We conclude that TLR genetic variants may modulate host susceptibility to melioidosis. Confirmation of these findings and further investigation of the mechanisms are required.
\end{abstract}

Genes and Immunity (2012) 13, 38-46; doi:10.1038/gene.2011.49; published online 21 July 2011

Keywords: melioidosis; Burkholderia pseudomallei; infection; Toll-like receptor; innate immunity; genetic variation

\section{Introduction}

Melioidosis is a tropical infection caused by the Gram-negative soil saprophyte Burkholderia pseudomallei. Disease may occur after bacterial inhalation, ingestion or cutaneous inoculation. Clinical manifestations are diverse but lung involvement is very common. ${ }^{1}$ Mortality from melioidosis in northeast Thailand is $40 \%$. Exposure to B. pseudomallei in northeast Thais appears widespread as seropositivity occurs in $\sim 70 \%$ of children by age 4 , but the annual incidence is about 21 cases per $100000 .^{2,3}$ Diabetes, present in about $50 \%$ of cases, is the main risk factor, but whether there are other explanations

Correspondence: Dr TE West, Division of Pulmonary \& Critical Care Medicine, Department of Medicine, Harborview Medical Center, University of Washington, Box 359640, 325 Ninth Ave, Seattle,

WA 98104, USA.

E-mail: tewest@u.washington.edu

Received 15 February 2011; revised 13 June 2011; accepted 22 June 2011; published online 21 July 2011 for the low incidence of disease given the high exposure to the bacterium remains unclear. ${ }^{1}$

A genetic influence on susceptibility to infection has been clearly established. ${ }^{4}$ Two small studies implicate genetic variation in susceptibility to melioidosis. 5,6 Previous human genetic studies of Gram-negative infections have predominantly examined sepsis of heterogeneous microbial etiologies rather than large populations with infections caused by a single bacterium. Genetic studies of pneumonia have similarly been limited by small sample sizes for any single pathogen. Study of host genetics in a large cohort of melioidosis subjects, including a sizable number of pneumonic cases, is therefore pertinent.

Toll-like receptors (TLRs) are pathogen-recognition receptors that initiate an inflammatory response upon ligation by conserved motifs on invading pathogens. ${ }^{7}$ TLR pathway genetic variation is associated with susceptibility to various infections or altered outcome from infection in numerous studies. ${ }^{8}$ Experimental data indicate that TLRs 2, 4 and 5 modulate the host response to B. pseudomallei, likely activated by bacterial 
lipopeptides, lipopolysaccharide (LPS) and flagellin, respectively. ${ }^{9,10}$ (West TE, unpublished data). TLRs 1 and 6 form heterodimers with TLR2. ${ }^{7}$ TIRAP (also known as MAL) is an adaptor molecule that is recruited upon ligation of TLRs 2 or $4 .^{7}$ We performed a casecontrol candidate gene study at a large referral hospital in northeast Thailand to test the hypothesis that variation in TLR pathway genes is associated with the development of melioidosis in a widely exposed population. The study was undertaken in two parts: First, a primary list of well-characterized single nucleotide polymorphisms (SNPS) in TLR pathway genes was defined and analyzed. Second, significant SNP associations prompted the analysis of additional variants from the pertinent gene regions.

\section{Results}

Four hundred and ninety B. pseudomallei culture-positive hospitalized cases, 950 non-hospitalized controls presenting to outpatient clinic or the blood donation center, and 458 B. pseudomallei culture-negative hospitalized controls with clinical signs of infection were identified at Sappasithiprasong Hospital, Ubon Ratchathani, Thailand. Characteristics of cases and controls are shown in Table 1.

We first tested the association between eight wellcharacterized TLR pathway gene SNPs and susceptibility to melioidosis in cases compared with non-hospitalized controls. These SNPs are either well defined functionally or have been associated with susceptibility or outcome to infection in multiple studies. ${ }^{8,11-26}$ Only $T L R 4_{1196 C>T}$ was significantly associated with melioidosis in a general genetic model comparing genotype frequencies $(P=0.05)$ (Table 2). In a dominant model adjusted for age, sex and diabetes status, the variant significantly conferred over a threefold protective effect (odds ratio (OR) 0.29, 95\% confidence interval $(\mathrm{CI}): 0.09-0.99, P=0.05)$. Unlike in Caucasian populations, $T L R 4_{1196 \mathrm{C}>\mathrm{T}}$ and $T L R 4_{896 \mathrm{~A}>\mathrm{G}}$ were not in very strong linkage disequilibrium (LD) $\left(r^{2}=0.69\right)$ and the minor allele frequency for each variant was $\sim 1 \%$. In the subgroups of cases with bacteremia or pulmonary involvement, no variants were significantly associated with disease (Supplementary Table 1).

We then tested the association of the primary SNPS with melioidosis compared with hospitalized controls. As most melioidosis cases were identified by screening hospitalized patients, this control group may better represent the source population. None of the SNPs was significantly associated with disease in unadjusted

Table 1 Characteristics of cases and controls

\begin{tabular}{lccc}
\hline & Cases & $\begin{array}{c}\text { Non-hospitalized } \\
\text { controls }\end{array}$ & $\begin{array}{c}\text { Hospitalized } \\
\text { controls }\end{array}$ \\
\hline Number & 490 & 950 & 458 \\
Median age (IQR) & $49(39-60)$ & $47(29-60)$ & $58(47-68)$ \\
Male (\%) & 51 & 48 & 51 \\
Diabetes (\%) & 56 & 50 & 28 \\
Bacteremia (\%) & 51 & & \\
Lung infection (\%) & 41 & &
\end{tabular}

Abbreviation: IQR, interquartile range. models, but in recessive models adjusted for age, sex and diabetes, associations of $T L R 1_{742 \mathrm{~A}>\mathrm{G}}$ and $T L R 1_{-7202 \mathrm{~A}>\mathrm{G}}$ with disease were significant (Table 2). In adjusted analyses, both of these variants were significantly associated with bacteremia, and $T L R 1_{742 \mathrm{~A}>\mathrm{G}}$ was associated with pulmonary involvement compared with hospitalized controls (Table 3). TLR $1_{742 \mathrm{~A}>\mathrm{G}}$ and TLR $1_{-7202 \mathrm{~A}>\mathrm{G}}$ were in high LD $\left(r^{2}=0.84\right)$ and had similar allele frequencies to $T L R 1_{742 \mathrm{~A}>\mathrm{G}}$ in a Vietnamese population. ${ }^{26}$ In these adjusted models, the effect of diabetes on case-control status was very strong (OR 3-4) (Tables 2 and 3), prompting us to evaluate whether a diabetesspecific effect of TLR1 variants existed. Further analyses were performed to test the association of each TLR1 SNP in melioidosis cases compared with hospitalized controls, stratifying by diabetes status. No significant associations were observed (Supplementary Table 2).

To test for population stratification between cases and controls, 25 independent SNPs from across the genome were genotyped. ${ }^{27}$ We conducted allelic analyses calculating the $\chi^{2}$ statistic for 24 of these SNPs (rs169479 had no variation) and determined the mean $\chi^{2}$ (Supplementary Table 3). For cases compared with nonhospitalized controls and to hospitalized controls, respectively, the mean $\chi^{2}$ was 1.18 and 0.96 . The proximity of these numbers to 1 suggested that minimal population stratification exists. ${ }^{28}$

Asian populations are underrepresented in studies of TLR pathway genetic variation and disease. Given the initial findings of associations of TLR4 and TLR1 variants with melioidosis, in the second phase of the study additional coding SNPs and haplotype-tagging SNPs in the TLR4 and TLR6-1-10 regions in Asian populations (selected as described in Materials and methods) were analyzed. Eight TLR4 region SNPs and 18 TLR6-1-10 region SNPs (Supplementary Table 4) were tested for associations with melioidosis compared with each of the two control groups.

Two of the eight TLR4 region SNPs showed an association with melioidosis (Table 4). rs10818066 was significantly associated with melioidosis in an unadjusted model when tested versus non-hospitalized controls but not when compared with hospitalized controls. In an adjusted model, the effect of the variant was significantly protective for both sets of control groups. When compared with each control group, rs960312 was significantly associated with disease in unadjusted models and the variant significantly increased susceptibility in adjusted models. Applying a conservative Bonferroni correction for multiple comparisons, several associations remained significant (Table 4). In subsequent adjusted analyses, rs10818066 was associated with bacteremic or pulmonary melioidosis when compared with either control group (Supplementary Table 5). rs960312 was associated with bacteremic and pulmonary melioidosis in unadjusted analyses when compared with hospitalized controls. In adjusted models, the variant was associated with pulmonary melioidosis compared with either control group.

None of the three significant TLR4 region variants, TLR $4_{1196 \mathrm{C}>\mathrm{T}}$, rs10818066 or rs960312, was in high LD with each other in the entire population (Figure 1). To examine the combined effects of these polymorphisms on melioidosis susceptibility, haplotypes with frequencies $>1 \%$ were constructed (Table 5). The association with disease 
Table 2 Associations of TLR pathway genetic variants with melioidosis

\begin{tabular}{|c|c|c|c|c|c|c|c|}
\hline \multirow[t]{2}{*}{$S N P$} & \multicolumn{4}{|c|}{ Unadjusted ${ }^{\text {a }}$} & \multicolumn{3}{|c|}{ Adjusted $^{\mathrm{b}}$} \\
\hline & & Genotype & & $\mathrm{P}$ & Model & OR $(95 \% \mathrm{CI})$ & $\mathrm{P}$ \\
\hline \multicolumn{8}{|l|}{$T L R 1_{742 \mathrm{~A}>\mathrm{G}}$} \\
\hline & $G / G$ & G/A & $\mathrm{A} / \mathrm{A}$ & & & & \\
\hline Cases & 126 & 246 & 117 & & & & \\
\hline Non-hospitalized controls & 271 & 459 & 215 & 0.50 & $\operatorname{Rec}$ & $1.09(0.84-1.41)$ & 0.53 \\
\hline Hospitalized controls & 133 & 230 & 93 & 0.31 & $\operatorname{Rec}$ & $1.44(1.02-2.03)$ & 0.04 \\
\hline \multicolumn{8}{|l|}{$T L R 1_{-7202 \mathrm{~A}>\mathrm{G}}$} \\
\hline & $G / G$ & G/A & $\mathrm{A} / \mathrm{A}$ & & & & \\
\hline Cases & 132 & 227 & 128 & & & & \\
\hline Non-hospitalized controls & 263 & 462 & 223 & 0.51 & $\operatorname{Rec}$ & $1.20(0.93-1.55)$ & 0.16 \\
\hline Hospitalized controls & 128 & 227 & 96 & 0.20 & $\operatorname{Rec}$ & $1.52(1.08-2.13)$ & 0.02 \\
\hline \multicolumn{8}{|l|}{$T L R 2_{597 \mathrm{C}>\mathrm{T}}$} \\
\hline & $\mathrm{T} / \mathrm{T}$ & $\mathrm{T} / \mathrm{C}$ & $\mathrm{C} / \mathrm{C}$ & & & & \\
\hline Cases & 302 & 160 & 23 & & & & \\
\hline Non-hospitalized controls & 603 & 301 & 37 & 0.68 & Dom & $1.05(0.83-1.32)$ & 0.68 \\
\hline Hospitalized controls & 294 & 147 & 14 & 0.39 & Dom & $1.10(0.82-1.48)$ & 0.51 \\
\hline \multicolumn{8}{|l|}{$T L R 4_{896 \mathrm{~A}>\mathrm{G}}$} \\
\hline Cases & $\mathrm{A} / \mathrm{A}$ & A/G & G/G & & & & \\
\hline $\begin{array}{l}\text { Cases } \\
\text { Non-hospitalized controls }\end{array}$ & 484 & 5 & 0 & & & & \\
\hline Non-hospitalized controls & 923 & 17 & 1 & 0.58 & Dom & $0.55(0.20-1.49)$ & 0.24 \\
\hline Hospitalized controls & 454 & 3 & 0 & 0.73 & Dom & $1.44(0.30-6.84)$ & 0.65 \\
\hline \multicolumn{8}{|l|}{$T L R 4_{1196 \mathrm{C}>\mathrm{T}}$} \\
\hline & $\mathrm{C} / \mathrm{C}$ & $\mathrm{C} / \mathrm{T}$ & $\mathrm{T} / \mathrm{T}$ & & & & \\
\hline Cases & 486 & 3 & 0 & & & & \\
\hline Non-hospitalized controls & 925 & 19 & 1 & 0.05 & Dom & $0.29(0.09-0.99)$ & 0.05 \\
\hline Hospitalized controls & 454 & 3 & 0 & 1.00 & Dom & $1.10(0.19-6.35)$ & 0.92 \\
\hline \multicolumn{8}{|l|}{$T L R 5_{1174 \mathrm{C}>\mathrm{T}}$} \\
\hline & $\mathrm{C} / \mathrm{C}$ & $\mathrm{C} / \mathrm{T}$ & $\mathrm{T} / \mathrm{T}$ & & & & \\
\hline Cases & 425 & 59 & 1 & & & & \\
\hline Non-hospitalized controls & 835 & 103 & 4 & 0.66 & Dom & $1.09(0.77-1.54)$ & 0.63 \\
\hline Hospitalized controls & 404 & 50 & 1 & 0.81 & Dom & $0.97(0.62-1.51)$ & 0.88 \\
\hline \multicolumn{8}{|l|}{$T I R A P_{539 \mathrm{C}>\mathrm{T}}$} \\
\hline & $\mathrm{C} / \mathrm{C}$ & $\mathrm{C} / \mathrm{T}$ & $\mathrm{T} / \mathrm{T}$ & & & & \\
\hline Cases & 461 & 25 & 0 & & & & \\
\hline Non-hospitalized controls & 898 & 45 & 1 & 0.87 & Dom & $1.02(0.61-1.70)$ & 0.94 \\
\hline Hospitalized controls & 436 & 21 & 0 & 0.76 & Dom & $1.39(0.72-2.71)$ & 0.33 \\
\hline \multicolumn{8}{|l|}{$T I R A P_{558 \mathrm{C}>\mathrm{T}}$} \\
\hline & $\mathrm{C} / \mathrm{C}$ & $\mathrm{C} / \mathrm{T}$ & $\mathrm{T} / \mathrm{T}$ & & & & \\
\hline Cases & 439 & 45 & 2 & & & & \\
\hline Non-hospitalized controls & 838 & 104 & 4 & 0.56 & Dom & $0.86(0.60-1.24)$ & 0.43 \\
\hline Hospitalized controls & 405 & 48 & 1 & 0.66 & Dom & $0.84(0.53-1.33)$ & 0.46 \\
\hline
\end{tabular}

Abbreviations: CI, confidence interval; OR, odds ratio; SNP, single nucleotide polymorphism; TLR, Toll-like receptor. ${ }^{a} \chi^{2}$ or, if cell count $<10$, Fisher's exact tests of association were performed for cases versus each control group.

${ }^{b}$ Dominant or recessive logistic regression models adjusted for age, sex and diabetes status were performed for cases versus each control group.

was examined compared with each of the two control groups using additive, dominant and recessive models. The effects observed were comparable to those attributable to rs10818066 or rs960312 in isolation.

The associations with disease of TLR6-1-10 region SNPs were examined, stratifying by diabetes status based on our initial analysis. There were few significant associations among subjects without diabetes (Supplementary Table 6) or in diabetics when comparing melioidosis cases to non-hospitalized controls (Table 6).
Comparing diabetic melioidosis cases with hospitalized diabetic controls, 3 of 16 SNPs in Hardy-Weinberg equilibrium were strongly associated with disease: rs2087465, rs3924112 and rs5743794 (Table 6). In adjusted models, these associations persisted. The association of rs2087465, a non-coding SNP in the TLR6 region, was significant even after applying a Bonferroni correction. In an adjusted analysis, the magnitude of protection conferred by this variant was particularly large (OR 0.13 , 95\% CI: $0.03-0.48, P=0.002$ ). 
Table 3 Associations of TLR1 variants with bacteremic or pulmonary melioidosis compared to hospitalized controls

\begin{tabular}{|c|c|c|c|c|c|c|c|}
\hline \multirow[t]{2}{*}{ SNP } & \multicolumn{4}{|c|}{ Unadjusted $^{\mathrm{a}}$} & \multicolumn{3}{|c|}{ Adjusted $^{\mathrm{b}}$} \\
\hline & & Genotype & & $\mathrm{P}$ & Model & OR $(95 \% C I)$ & $\mathrm{P}$ \\
\hline \multicolumn{8}{|l|}{$T L R 1_{742 \mathrm{~A}>\mathrm{G}}$} \\
\hline & $\mathrm{G} / \mathrm{G}$ & $\mathrm{G} / \mathrm{A}$ & $\mathrm{A} / \mathrm{A}$ & & & & \\
\hline Bacteremic cases & 74 & 114 & 60 & 0.42 & $\operatorname{Rec}$ & $1.52(1.00-2.30)$ & 0.05 \\
\hline Hospitalized controls & 133 & 230 & 93 & & & & \\
\hline \multicolumn{8}{|l|}{$T L R 1_{-7202 \mathrm{~A}>\mathrm{G}}$} \\
\hline & $\mathrm{G} / \mathrm{G}$ & $\mathrm{G} / \mathrm{A}$ & $\mathrm{A} / \mathrm{A}$ & & & & \\
\hline Bacteremic cases & 74 & 107 & 65 & 0.17 & $\operatorname{Rec}$ & $1.55(1.03-2.34)$ & 0.04 \\
\hline Hospitalized controls & 128 & 227 & 96 & & & & \\
\hline \multicolumn{8}{|l|}{$T L R 1_{742 \mathrm{~A}>\mathrm{G}}$} \\
\hline & G/G & G/A & $\mathrm{A} / \mathrm{A}$ & & & & \\
\hline Pulmonary cases & 46 & 111 & 39 & 0.27 & Dom & $1.59(1.04-2.41)$ & 0.03 \\
\hline Hospitalized controls & 133 & 230 & 93 & & & & \\
\hline \multicolumn{8}{|l|}{$T L R 1_{-7202 \mathrm{~A}>\mathrm{G}}$} \\
\hline & G/G & G/A & $\mathrm{A} / \mathrm{A}$ & & & & \\
\hline Pulmonary cases & 51 & 105 & 40 & 0.74 & Dom & $1.40(0.93-2.12)$ & 0.11 \\
\hline Hospitalized controls & 128 & 227 & 96 & & & & \\
\hline
\end{tabular}

Abbreviations: CI, confidence interval; OR, odds ratio; SNP, single nucleotide polymorphism.

${ }^{a} \chi^{2}$ or, if cell count $<10$, Fisher's exact tests of association were performed.

${ }^{\mathrm{b}}$ Dominant or recessive logistic regression models were adjusted for age, sex and diabetes status.

None of these three SNPs was in strong LD with each other $\left(r^{2}\right.$ for each pair <0.7). Haplotypes were constructed with all three SNPs and the association with disease was tested in hospitalized diabetics. The additive model haplotype comprised of the rare allele at all three loci occurring in $21 \%$ of controls, resulted in the largest significant effect (OR 0.49, 95\% CI: 0.33-0.75, $P=0.001$ ).

\section{Discussion}

This study of nearly 1900 Thais at risk for melioidosis is the largest study of human genetic variants and susceptibility to melioidosis, and the first to examine genetic variations in pattern recognition receptor pathways. This study is also notable as one of the few large investigations of host genetic factors underlying Gram-negative infection. Based on an abundant literature implicating TLR pathway variants in susceptibility to or outcome from infection, this pathway was targeted in our analysis of melioidosis patients. Our main findings are that TLR4 region gene variants are associated with melioidosis, and in hospitalized diabetics, TLR6-1-10 gene variants are associated with differential susceptibility to melioidosis than to other illnesses.

As the primary host receptor for LPS, TLR4 is the canonical TLR for Gram-negative pathogens. B. pseudomallei is a Gram-negative pathogen that induces an inflammatory response that is TLR4-dependent, and B. pseudomallei lipopolysaccharide is a TLR4 agonist. ${ }^{9}$ Therefore, there is compelling in vitro evidence for the importance of TLR4 in melioidosis. The role of TLR4 in mouse models of respiratory Burkholderia infection is less apparent, ${ }^{10,29}$ but in human cases of melioidosis, TLR4, MD2 and CD14 are all expressed at higher levels than in controls. ${ }^{10}$
Polymorphisms in TLR4 have been extensively studied. ${ }^{8}$ The two best-known SNPs are at positions 896 and 1196. They are typically in high LD in Caucasian populations, where they occur more frequently than in Asian populations. Several studies suggest that these SNPs are associated with susceptibility to sepsis ${ }^{18,30}$ but not to meningococcal or pneumococcal infection. ${ }^{31-35}$ The SNPs are linked with resistance to legionellosis and to recurrent urinary tract infections. ${ }^{23,36}$ Thus their role may be population- and infection-specific. In this study, a substantial protective effect of the extremely rare $T L R 4_{1196 C>T}$ allele was observed when compared with non-hospitalized controls but not in comparison with hospitalized controls. A likely explanation is that many hospitalized control subjects had other infections or undiagnosed melioidosis that are similarly associated with a lower frequency of the minor allele. A role for TLR4 in human melioidosis is greatly supported by our additional findings of an association with disease attributable to two other TLR4 region variants, regardless of control group chosen for comparison. The rs10818066 variant also conferred protection against melioidosis but the rs960312 variant was associated with susceptibility to disease. A comparable pattern of effect for $T L R 4_{1196 \mathrm{C}>\mathrm{T}}$ and rs960312 was observed in a study of genetic associations with liver fibrosis in Caucasians. ${ }^{37}$ That rs10818066 and rs960312 are located in intergenic regions and are not in LD with $T L R 4_{1196 C>T}$ suggests that these SNPs are in LD with other unidentified causative variants. We hypothesize that altered TLR4-dependent host responses to $B$. pseudomallei lipopolysaccharide in carriers of these causative variants modulate host susceptibility to successful infection by the invading pathogen. Resequencing of the TLR4 region in this littlestudied population and careful assessments of functional effects of variants will be required to further test this 
Table 4 Associations of TLR4 region variants with melioidosis

\begin{tabular}{|c|c|c|c|c|c|c|c|}
\hline \multirow[t]{2}{*}{ SNP } & \multicolumn{4}{|c|}{ Unadjusted $^{\text {a }}$} & \multicolumn{3}{|c|}{ Adjusted $^{\mathrm{b}}$} \\
\hline & & Genotype & & $\mathrm{P}^{c}$ & Model & OR $(95 \% C I)$ & $\mathrm{P}$ \\
\hline \multicolumn{8}{|l|}{ rs10818066 } \\
\hline & $\mathrm{T} / \mathrm{T}$ & $\mathrm{T} / \mathrm{C}$ & $\mathrm{C} / \mathrm{C}$ & & & & \\
\hline Cases & 178 & 256 & 55 & 0.006 & $\operatorname{Rec}$ & $0.58(0.42-0.81)$ & 0.001 \\
\hline Non-hospitalized controls & 345 & 434 & 163 & & & & \\
\hline Hospitalized controls & 159 & 222 & 76 & 0.06 & $\operatorname{Rec}$ & $0.59(0.40-0.89)$ & 0.012 \\
\hline \multicolumn{8}{|l|}{ rs7864330 } \\
\hline & $\mathrm{T} / \mathrm{T}$ & $\mathrm{T} / \mathrm{G}$ & $\mathrm{G} / \mathrm{G}$ & & & & \\
\hline Cases & 477 & 10 & 0 & 0.50 & Dom & $0.64(0.31-1.33)$ & 0.23 \\
\hline Non-hospitalized controls & 918 & 30 & 1 & & & & \\
\hline Hospitalized controls & 441 & 14 & 0 & 0.41 & Dom & $0.58(0.24-1.40)$ & 0.23 \\
\hline \multicolumn{8}{|l|}{ rs1329061 } \\
\hline & $\mathrm{T} / \mathrm{T}$ & $\mathrm{T} / \mathrm{C}$ & $\mathrm{C} / \mathrm{C}$ & & & & \\
\hline Cases & 269 & 188 & 32 & & & & \\
\hline Non-hospitalized controls & 549 & 334 & 64 & 0.49 & Dom & $1.11(0.89-1.39)$ & 0.35 \\
\hline Hospitalized controls & 264 & 171 & 22 & 0.44 & $\operatorname{Rec}$ & $1.27(0.69-2.33)$ & 0.44 \\
\hline \multicolumn{8}{|l|}{ rs16905939 } \\
\hline & $\mathrm{A} / \mathrm{A}$ & A/G & $\mathrm{G} / \mathrm{G}$ & & & & \\
\hline Cases & 375 & 109 & 4 & & & & \\
\hline Non-hospitalized controls & 719 & 208 & 19 & 0.25 & $\operatorname{Rec}$ & $0.41(0.14-1.23)$ & 0.11 \\
\hline Hospitalized controls & 350 & 97 & 9 & 0.32 & $\operatorname{Rec}$ & $0.30(0.09-1.03)$ & 0.06 \\
\hline \multicolumn{8}{|l|}{ rs1927906 } \\
\hline & $\mathrm{A} / \mathrm{A}$ & A/G & $\mathrm{G} / \mathrm{G}$ & & & & \\
\hline Cases & 467 & 18 & 1 & & & & \\
\hline Non-hospitalized controls & 890 & 58 & 1 & 0.09 & Dom & $0.65(0.38-1.11)$ & 0.11 \\
\hline Hospitalized controls & 434 & 21 & 0 & 0.57 & Dom & $0.75(0.38-1.49)$ & 0.41 \\
\hline \multicolumn{8}{|l|}{ rs7021687 } \\
\hline & G/G & $\mathrm{G} / \mathrm{A}$ & $\mathrm{A} / \mathrm{A}$ & & & & \\
\hline Cases & 458 & 27 & 1 & & & & \\
\hline Non-hospitalized controls & 889 & 57 & 1 & 0.83 & $\operatorname{Rec}$ & $1.76(0.11-28.3)$ & 0.69 \\
\hline Hospitalized controls & 422 & 32 & 0 & 0.42 & Dom & $0.88(0.49-1.56)$ & 0.65 \\
\hline \multicolumn{8}{|l|}{ rs756135 } \\
\hline & $\mathrm{A} / \mathrm{A}$ & $\mathrm{G} / \mathrm{A}$ & $\mathrm{G} / \mathrm{G}$ & & & & \\
\hline Cases & 428 & 61 & 1 & & & & \\
\hline Non-hospitalized controls & 823 & 119 & 4 & 0.93 & $\operatorname{Rec}$ & $0.43(0.05-3.87)$ & 0.45 \\
\hline Hospitalized controls & 394 & 60 & 3 & 0.58 & $\operatorname{Rec}$ & $0.36(0.30-4.42)$ & 0.43 \\
\hline \multicolumn{8}{|l|}{ rs960312 } \\
\hline & $\mathrm{A} / \mathrm{A}$ & $\mathrm{A} / \mathrm{G}$ & $\mathrm{G} / \mathrm{G}$ & & & & \\
\hline Cases & 358 & 122 & 9 & & & & \\
\hline Non-hospitalized controls & 750 & 177 & 15 & 0.02 & Dom & $1.39(1.07-1.81)$ & 0.01 \\
\hline Hospitalized controls & 370 & 85 & 2 & 0.005 & Dom & $1.45(1.03-2.04)$ & 0.03 \\
\hline
\end{tabular}

Abbreviations: $\mathrm{CI}$, confidence interval; OR, odds ratio; SNP, single nucleotide polymorphism.

${ }^{a} \chi^{2}$ or, if cell count $<10$, Fisher's exact tests of association were performed for cases versus each control group.

bominant or recessive logistic regression models adjusted for age, sex and diabetes status were performed for cases versus each control group.

'Tests meeting significance after Bonferroni correction $(0.05 / 8=0.00625)$ for multiple comparisons are in bold.

hypothesis. In aggregate, these data provide the strongest evidence to date that TLR4 is an important element of host defense in human melioidosis.

Our data also suggest that in diabetics, TLR6-1-10 region variants regulate differential susceptibility to melioidosis compared with other illnesses. While the function of TLR10 in humans remains unclear, TLRs 1 and 6 form heterodimers with TLR2 to permit signaling upon ligation by bacterial cell wall components. Both TLRs 1 and 6 augment TLR2-dependent signaling upon stimulation with heat-killed B. pseudomallei. ${ }^{9}$ TLR2 deficiency may heighten the cytokine response to B. pseudomallei in macrophages and confers protection in murine studies of respiratory infection. ${ }^{9,10}$ In Caucasians, the high LD TLR1 SNPs TLR1 $1_{742 \mathrm{~A}>\mathrm{G}}, T L R 1_{-7202 \mathrm{~A}>\mathrm{G}}$ and $T L R 1_{1804 \mathrm{G}>\mathrm{T}}$ are linked with immunomodulatory effects and sepsis outcomes. ${ }^{13,26}$ Diabetes is a defined risk factor for melioidosis, and studies have demonstrated B. pseudomallei-specific defects in neutrophil functions such as phagocytosis, reduced chemotaxis and resistance 
to apoptosis. ${ }^{38}$ Altered TLR signaling occurs in diabetics ${ }^{39}$ but this has not been extensively studied during infection. Here, we demonstrate that in diabetics, TLR61-10 region variants are associated with differential susceptibility to melioidosis than to other illnesses. We did not find that these variants are associated with susceptibility to melioidosis compared with otherwise healthy subjects. Homozygosity of the rs2087465 minor allele confers a nearly eight-fold protective effect against melioidosis in hospitalized diabetics. As the frequency of this allele is comparable in diabetics with melioidosis and in otherwise healthy diabetics, however, an alternative explanation is that this allele markedly heightens susceptibility to non-melioidosis illness in diabetics. Review of available diagnoses in the hospitalized diabetic controls revealed a large spectrum of infectious illnesses, including pneumonia, sepsis, tuberculosis, leptospirosis, as well as non-infectious processes. Thus, our data provide evidence that the relative importance of different innate immune receptors may vary depending

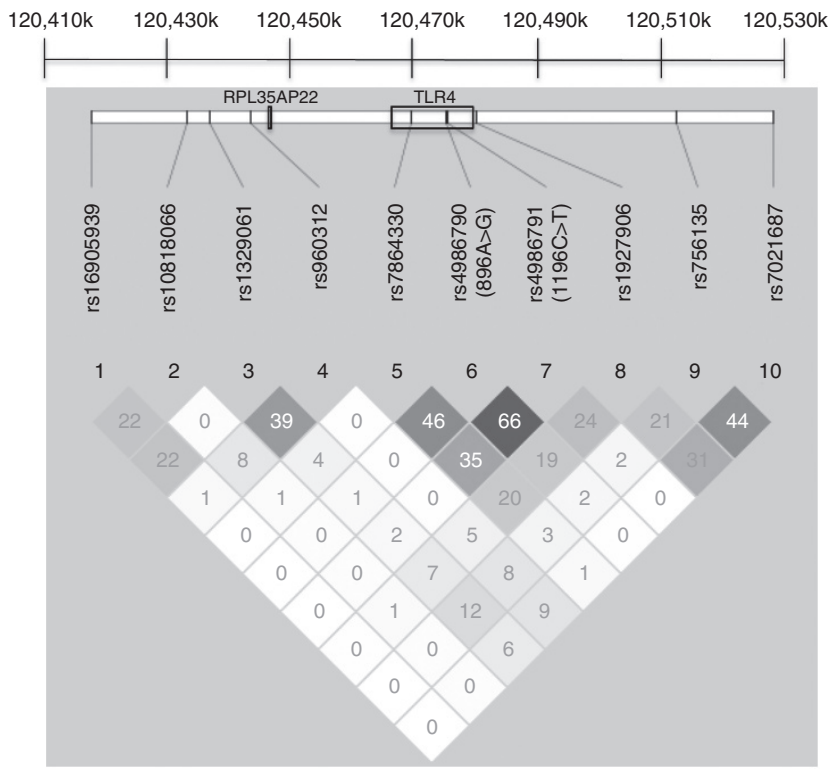

Figure 1 LD of TLR4 region SNPs in Thais. Genetic map indicates location of SNPs relative to TLR4 on chromosome 9. Numbers within LD map denote $r^{2}$ values. Figure generated by Haploview and modified.

Table 5 TLR4 region haplotype

\begin{tabular}{|c|c|c|c|}
\hline \multirow[t]{2}{*}{ Haplotype $^{\mathrm{a}}$} & \multicolumn{3}{|c|}{ TLR4 $_{1196 C>T \_r s 10818066 \_r s 960312}$} \\
\hline & 000 & 001 & 010 \\
\hline Frequency in non-hospitalized controls & 0.48 & 0.11 & 0.40 \\
\hline Odds ratio $(95 \% \mathrm{CI})^{\mathrm{b}}$ & $1.01(0.87-1.18)$ & $1.40(1.09-1.80)$ & $0.64(0.48-0.88)$ \\
\hline$P$ & 0.89 & 0.009 & 0.004 \\
\hline Frequency in hospitalized controls & 0.49 & 0.09 & 0.41 \\
\hline Odds ratio $(95 \% \mathrm{CI})^{\mathrm{b}}$ & $0.96(0.80-1.14)$ & $1.58(1.18-2.14)$ & $0.62(0.45-0.86)$ \\
\hline$P$ & 0.62 & 0.003 & 0.004 \\
\hline
\end{tabular}

on underlying diseases as well as on specific infection. Additional study of genetic variation in TLR6-1-10 in both non-diabetics and diabetics in this population is indicated.

There are several limitations to this study. It is possible that our cases were not selected from the same population as controls - a rationale for selecting two control groups-but we did not observe significant population stratification. The exposure of the cases and controls may have differed but studies have shown widespread seropositivity to $B$. pseudomallei in the local population. ${ }^{2}$ While replicating genetic associations in another cohort is desirable, there are few locations where a comparable study of melioidosis host genetics could be undertaken. Thus, as large a study as possible with multiple control groups was designed. The results underscore the importance of generating additional genetic data in Thai and other southeast Asian populations.

In conclusion, TLR4 genetic variants are associated with melioidosis in a Thai population. In diabetic populations, TLR6-1-10 variants are associated with differential susceptibility to melioidosis compared with other illnesses. Further investigations of causative genetic variants and mechanisms of susceptibility in this population are required.

\section{Materials and methods}

Clinical study design

Cases $(n=490)$ were identified among inpatients at Sappasithiprasong Hospital, Ubon Ratchathani, northeast Thailand from 1999 to 2005. A study team screening patients with clinical signs of infection cultured blood, urine and other relevant samples (for example, abscess aspirates) for B. pseudomallei ${ }^{40}$ Case status was defined by a positive culture for $B$. pseudomallei from a sample collected by the study team or independently by hospital clinicians. Two separate groups of control subjects were defined. The first group totaled 950 non-hospitalized subjects. As the majority of melioidosis cases have underlying diabetes, this control group combined 475 healthy individuals who presented to the blood donation center and 475 otherwise healthy diabetics recruited from the outpatient diabetes clinic at the hospital between 2007 and 2008. A second control group was comprised of 458 hospitalized subjects with clinical signs of infection who were screened for melioidosis by the

Abbreviation: CI, confidence interval.

${ }^{a} 1$ indicates presence of rare allele at each locus. Frequency of all other haplotypes $<1 \%$.

${ }^{\mathrm{b}}$ Additive model for 000 , dominant model for 001 and recessive model for 010 . 
Table 6 Associations of TLR6-1-10 region variants with melioidosis in diabetics

\begin{tabular}{|c|c|c|c|c|c|}
\hline \multirow[t]{2}{*}{ SNP } & \multirow[t]{2}{*}{ Control group } & \multicolumn{2}{|c|}{ Unadjusted } & \multicolumn{2}{|l|}{ Adjusted } \\
\hline & & $\mathrm{P}^{\mathrm{b}, \mathrm{c}}$ & Model $^{\mathrm{d}}$ & OR $(95 \% \mathrm{CI})$ & $\mathrm{P}^{\mathrm{c}}$ \\
\hline \multirow[t]{2}{*}{ rs721653 } & Non-hospitalized & 0.97 & Dom & $1.05(0.75-1.46)$ & 0.78 \\
\hline & Hospitalized & 0.72 & Dom & $0.86(0.54-1.38)$ & 0.54 \\
\hline \multirow[t]{2}{*}{ rs2087465 } & Non-hospitalized & 0.97 & $\operatorname{Rec}$ & $0.92(0.26-3.14)$ & 0.90 \\
\hline & Hospitalized & 0.002 & $\operatorname{Rec}$ & $0.13(0.03-0.48)$ & 0.002 \\
\hline rs3775073 & $\begin{array}{l}\text { Non-hospitalized } \\
\text { Hospitalized }^{*}\end{array}$ & 0.50 & Dom & $1.24(0.85-1.82)$ & 0.25 \\
\hline \multirow[t]{2}{*}{ rs3924112 } & Non-hospitalized & 0.88 & Dom & $0.83(0.60-1.16)$ & 0.27 \\
\hline & Hospitalized & 0.04 & $\operatorname{Rec}$ & 10 & 0.007 \\
\hline \multirow[t]{2}{*}{ rs4274855 } & Non-hospitalized & 0.74 & Dom & $0.74(0.50-1.10)$ & 0.14 \\
\hline & Hospitalized & 0.27 & Dom & $0.61(0.36-1$ & 0.06 \\
\hline \multirow[t]{2}{*}{ rs4321646 } & Non-hospi & 0.97 & $\operatorname{Rec}$ & $1.23(0.49-3.06)$ & 0.66 \\
\hline & Hospit & 0.65 & Dom & $1.30(0.78-2$ & 0.32 \\
\hline \multirow[t]{2}{*}{ rs5743794 } & Non-hospi & 0.59 & $\operatorname{Rec}$ & $0.66(0.31-1.42)$ & 0.29 \\
\hline & Hospi & 0.02 & $\operatorname{Rec}$ & $0.30(0.11-0$ & 0.01 \\
\hline \multirow[t]{2}{*}{ rs5743808 } & Non-hospitalized & 0.09 & Dom & $1.37(0.95-1.98)$ & 0.09 \\
\hline & Hospit & 0.18 & Dom & $1.68(0.97-2.90)$ & 0.07 \\
\hline rs5743831 & $\begin{array}{l}\text { Non-hospitalized } \\
\text { Hospitalized* }^{*}\end{array}$ & 0.32 & Dom & $0.80(0.58-1.11)$ & 0.19 \\
\hline \multirow{2}{*}{ rs11096957 } & Non-hospitalized & 0.83 & Dom & $0.87(0.60-1.26)$ & 0.87 \\
\hline & Hospitalized & & & & 0.2 \\
\hline \multirow[t]{2}{*}{ rs11096964 } & Non-hospitalized & 0.13 & Dom & $1.48(0.96-2.27)$ & 0.07 \\
\hline & Hospitalized & 0.11 & Do & $1.76(0.92-3.36)$ & 0.09 \\
\hline \multirow[t]{2}{*}{ rs11466651 } & Non-hospitalized & 0.58 & Dom & $0.79(0.55-1.15)$ & 0.22 \\
\hline & Hospitalized & 0.22 & Dom & $0.69(0.41-1.16)$ & 0.16 \\
\hline \multirow[t]{2}{*}{ rs11466653 } & Non-hospitalized & 0.63 & Dom & $0.82(0.57-1.19)$ & 0.30 \\
\hline & Hospitalized & 0.23 & Dom & $0.73(0.44-1.22)$ & 0.23 \\
\hline \multirow[t]{2}{*}{ rs11466655 } & Non-hospitalized & 0.90 & $\operatorname{Rec}$ & $1.18(0.66-2.10)$ & 0.58 \\
\hline & Hospitalized & 0.30 & $\operatorname{Rec}$ & $2.71(0.96-7.64)$ & 0.06 \\
\hline \multirow[t]{2}{*}{ rs11944159 } & Non-hospitalized & 0.09 & Dom & $1.56(1.02-2.39)$ & 0.04 \\
\hline & Hospitalized & 0.10 & Dom & $1.18(0.95-3.47)$ & 0.07 \\
\hline \multirow[t]{2}{*}{ rs 17429224} & Non-hospitalized & 0.20 & Dom & $1.39(1.00-1.94)$ & 0.05 \\
\hline & Hospitalized & 0.12 & $\operatorname{Rec}$ & $0.40(0.16-1.00)$ & 0.05 \\
\hline \multirow[t]{2}{*}{ rs17429273 } & Non-hospitalized & 0.67 & Dom & $1.86(0.32-10.65)$ & 0.49 \\
\hline & Hospitalized & 1.00 & Dom & $0.71(0.07-7.36)$ & 0.78 \\
\hline \multirow[t]{2}{*}{ rs17616434 } & Non-hospitalized & 0.65 & $\operatorname{Rec}$ & $1.22(0.82-1.81)$ & 0.32 \\
\hline & Hospitalized & 0.19 & $\operatorname{Rec}$ & $1.54(0.85-2.80)$ & 0.15 \\
\hline
\end{tabular}

Abbreviations: CI, confidence interval; OR, odds ratio; SNP, single nucleotide polymorphism.

${ }^{a *}$ denotes deviation from Hardy-Weinberg equilibrium.

${ }^{b} \chi^{2}$ or, if cell count $<10$, Fisher's exact tests of association were performed for cases versus controls.

'Tests meeting significance after Bonferroni correction $(0.05 / 16=$ 0.003 ) for multiple comparisons are in bold.

${ }^{\mathrm{d}}$ Dominant or recessive logistic regression models were adjusted for age and sex.

study team but were culture negative for B. pseudomallei. An exclusion criterion for all control subjects was a previous history of melioidosis. The University of Washington Human Subjects Division Institutional Review Board, Ethical Review Committee for Research in Human Subjects, Ministry of Public Health, Thailand, and the Ethics Committee of the Faculty of Tropical Medicine, Mahidol University, Bangkok, Thailand approved this study.

\section{Genomic methods}

From the literature, SNPs in TLR pathway genes (TLR1, TLR2, TLR4, TLR5 and TIRAP) with well-defined functional effects or associated with altered susceptibility to or outcome from infection were identified. Owing to little published data on genetic variation in Thais, additional SNP identification and selection was performed using the Genome Variation Server (http:// gvs.gs.washington.edu/GVS/). Coding SNPs in candi- date genes were selected. Within the region encompassed by 50000 bases upstream and downstream of each candidate gene, SNPs with a minor allele frequency $\geqslant 2 \%$ in populations identified as Japanese, Chinese and Asian were binned into groups with $r^{2} \geqslant 0.8$ to identify haplotype-tagging SNPs. DNA was extracted from whole blood using Nucleon BACC3 kits (GE Healthcare, Buckinghamshire, UK). Genotyping was performed using an allele-specific primer extension method (Sequenom Inc., San Diego, CA, USA) with reads by a MALDITOF mass spectrometer. ${ }^{41}$

\section{Statistical methods}

The study analysis was undertaken in two phases. First, a primary list of SNPs was defined: TIRAP $539 \mathrm{C}>\mathrm{T}$, TIRAP ${ }_{558 \mathrm{C}>\mathrm{T},}, \quad T L R 1_{1804 \mathrm{G}>\mathrm{T}}, \quad T L R 2_{597 \mathrm{C}>\mathrm{T}}, \quad T L R 2_{2258 \mathrm{G}>\mathrm{A}}$, $T L R 4_{896 \mathrm{~A}>\mathrm{G}}{ }$ TLR $4_{1196 \mathrm{C}>\mathrm{T}}$ and TLR5 $5_{1174 \mathrm{C}>\mathrm{T}}$. Each SNP has either been associated with susceptibility to infection or outcome from infection in a previous study or has been shown to regulate cell function. ${ }^{11-25}$ In Caucasian populations, $T L R 1_{1804 \mathrm{G}>\mathrm{T}}$ is in high LD with two other TLR1 SNPs: TLR1 $1_{742 \mathrm{~A}>\mathrm{G}}$, another non-synonymous coding SNP, and TLR1 $1_{-7202 \mathrm{~A}>\mathrm{G}}$, a tagging $\mathrm{SNP}, 13,26$ although $T L R 1_{742 \mathrm{~A}>\mathrm{G}}$ and $T L R 1_{1804 \mathrm{G}>\mathrm{T}}$ are not in LD in a Vietnamese population. ${ }^{26}$ TLR $_{1804 \mathrm{G}>\mathrm{T}}$ could not be readily accommodated in our plex design, so both $T L R 1_{742 \mathrm{~A}>\mathrm{G}}$ and $T L R 1_{-7202 \mathrm{~A}>\mathrm{G}}$ were genotyped instead. The minor allele frequency for TLR2 $2258 \mathrm{G}>\mathrm{A}$ was $0 \%$ in our population. Therefore, the eight final SNPs analyzed were: TIRAP ${ }_{539 \mathrm{C}>\mathrm{T}}(\mathrm{rs} 8177374)$, TIRAP $_{558 \mathrm{C}>\mathrm{T}}(\mathrm{rs} 7932766)$, $T L R 1_{742 \mathrm{~A}>\mathrm{G}}(\mathrm{rs} 4833095), T L R 1_{-7202 \mathrm{~A}>\mathrm{G}}(\mathrm{rs} 5743551), \mathrm{TLR} 2_{597 \mathrm{C}>\mathrm{T}}$ (rs3804099), TLR4 $4_{896 \mathrm{~A}>\mathrm{G}}(\mathrm{rs} 4986790), T L R 4_{1196 \mathrm{C}>\mathrm{T}}(\mathrm{rs} 4986791)$ and TLR5 ${ }_{1174 C>T}$ (rs5744168). The frequency of these SNPs was compared in cases versus controls. Based on the initial results suggesting hits for TLR4 and TLR1 SNPs, additional variants in these genes were examined in the second phase of the analysis. TLR1 is part of a locus comprising TLR6, TLR1 and TLR10, so SNPs from this entire locus were selected. The secondary SNPs are listed in Supplementary Table 4.

SNPs were first examined for deviation from HardyWeinberg equilibrium in the control populations studied using the Fisher's exact test. The association between genotype and disease was analyzed using a $\chi^{2}$ test except when cell values in the table were $<10$, in which case the Fisher's exact test was chosen. Logistic regression was performed with an appropriate genetic model (dominant or recessive), adjusting for age, sex and (where suitable) diabetes status. In the initial study phase, two additional analyses were performed defining cases as the subgroup of patients with bacteremia or as those with lung involvement or pleural effusions. No adjustment was made for multiple comparisons in this initial phase because of previously demonstrated associations or functional effect of each of the eight primary SNPs. Twenty-five unrelated SNPs from across the genome were genotyped and the mean $\chi^{2}$ statistic for the comparison of allele frequencies between cases and non-hospitalized controls was examined as a measure of population stratification..$^{27,28}$ In the subsequent study phase, a conservative Bonferroni correction was applied to multiple comparisons to maintain the desired familywise type I error rate. Unadjusted haplotypes containing relevant variants were constructed using additive, dominant, or recessive models. All analyses were 
performed with Stata version 11.1 (College Station, TX, USA) incorporating pwld, genhw and haplologit functions. $P$-values $\leqslant 0.05$ were considered significant. LD mapping was performed with Haploview v4.2. ${ }^{42}$

\section{Conflict of interest}

The authors declare no conflict of interest.

\section{Acknowledgements}

The authors acknowledge the support of the staff and patients at Sappasithiprasong Hospital; DNA extraction by Premjit Amornchai, Aunchalee Thanwisai and Malinee Oyuchua; genotyping by Sarah Li and Marta Janer; Stata support from Tony Black and Brad Glavan; and comments from Mark Wurfel. This work was supported by National Institutes of Health awards HL094759 and AI057141, the Puget Sound Partners for Global Health, the Parker B Francis Foundation and the Wellcome Trust.

\section{References}

1 Wiersinga WJ, van der Poll T, White NJ, Day NP, Peacock SJ. Melioidosis: insights into the pathogenicity of Burkholderia pseudomallei. Nat Rev Microbiol 2006; 4: 272-282.

2 Wuthiekanun V, Chierakul W, Langa S, Chaowagul W, Panpitpat C, Saipan P et al. Development of antibodies to Burkholderia pseudomallei during childhood in melioidosisendemic northeast Thailand. Am J Trop Med Hyg 2006; 74: 1074-1075.

3 Limmathurotsakul D, Wongratanacheewin S, Teerawattanasook N, Wongsuvan G, Chaisuksant S, Chetchotisakd P et al. Increasing incidence of human melioidosis in Northeast Thailand. Am J Trop Med Hyg 2010; 82: 1113-1117.

4 Sorensen TI, Nielsen GG, Andersen PK, Teasdale TW. Genetic and environmental influences on premature death in adult adoptees. N Engl J Med 1988; 318: 727-732.

5 Nuntayanuwat S, Dharakul T, Chaowagul W, Songsivilai S. Polymorphism in the promoter region of tumor necrosis factor-alpha gene is associated with severe meliodosis. Hum Immunol 1999; 60: 979-983.

6 Dharakul T, Vejbaesya S, Chaowagul W, Luangtrakool P, Stephens HA, Songsivilai S. HLA-DR and -DQ associations with melioidosis. Hum Immunol 1998; 59: 580-586.

7 Kawai T, Akira S. The role of pattern-recognition receptors in innate immunity: update on toll-like receptors. Nat Immunol 2010; 11: 373-384.

8 Misch EA, Hawn TR. Toll-like receptor polymorphisms and susceptibility to human disease. Clin Sci (Lond) 2008; 114: $347-360$.

9 West TE, Ernst RK, Jansson-Hutson MJ, Skerrett SJ. Activation of toll-like receptors by Burkholderia pseudomallei. BMC Immunol 2008; 9: 46.

10 Wiersinga WJ, Wieland CW, Dessing MC, Chantratita N, Cheng AC, Limmathurotsakul D et al. Toll-like receptor 2 impairs host defense in gram-negative sepsis caused by Burkholderia pseudomallei (Melioidosis). PLoS Med 2007; 4: e248.

11 Khor CC, Chapman SJ, Vannberg FO, Dunne A, Murphy C, Ling EY et al. A Mal functional variant is associated with protection against invasive pneumococcal disease, bacteremia, malaria and tuberculosis. Nat Genet 2007; 39: 523-528.

12 Hawn TR, Dunstan SJ, Thwaites GE, Simmons CP, Thuong NT, Lan NT et al. A polymorphism in Toll-interleukin 1 receptor domain containing adaptor protein is associated with susceptibility to meningeal tuberculosis. J Infect Dis 2006; 194: 1127-1134

13 Wurfel MM, Gordon AC, Holden TD, Radella F, Strout J, Kajikawa $\mathrm{O}$ et al. Toll-like receptor 1 polymorphisms affect innate immune responses and outcomes in sepsis. Am J Respir Crit Care Med 2008; 178: 710-720.

14 Schroder NW, Diterich I, Zinke A, Eckert J, Draing C, von Baehr $\mathrm{V}$ et al. Heterozygous Arg753Gln polymorphism of human TLR-2 impairs immune activation by Borrelia burgdorferi and protects from late stage Lyme disease. J Immunol 2005; 175: 2534-2540.

15 Ogus AC, Yoldas B, Ozdemir T, Uguz A, Olcen S, Keser I et al. The Arg753GLn polymorphism of the human toll-like receptor 2 gene in tuberculosis disease. Eur Respir J 2004; 23: 219-223.

16 Kutukculer N, Yeniay BS, Aksu G, Berdeli A. Arg753Gln polymorphism of the human toll-like receptor-2 gene in children with recurrent febrile infections. Biochem Genet 2007; 45: 507-514.

17 Lorenz E, Mira JP, Frees KL, Schwartz DA. Relevance of mutations in the TLR4 receptor in patients with gram-negative septic shock. Arch Intern Med 2002; 162: 1028-1032.

18 Agnese DM, Calvano JE, Hahm SJ, Coyle SM, Corbett SA, Calvano SE et al. Human toll-like receptor 4 mutations but not CD14 polymorphisms are associated with an increased risk of gram-negative infections. I Infect Dis 2002; 186: 1522-1525.

19 Barber RC, Aragaki CC, Rivera-Chavez FA, Purdue GF, Hunt JL, Horton JW. TLR4 and TNF-alpha polymorphisms are associated with an increased risk for severe sepsis following burn injury. J Med Genet 2004; 41: 808-813.

20 Yuan FF, Marks K, Wong M, Watson S, de Leon E, McIntyre PB et al. Clinical relevance of TLR2, TLR4, CD14 and FcgammaRIIA gene polymorphisms in Streptococcus pneumoniae infection. Immunol Cell Biol 2008; 86: 268-270.

21 Hawn TR, Wu H, Grossman JM, Hahn BH, Tsao BP, Aderem A. A stop codon polymorphism of toll-like receptor 5 is associated with resistance to systemic lupus erythematosus. Proc Natl Acad Sci USA 2005; 102: 10593-10597.

22 Hawn TR, Verbon A, Lettinga KD, Zhao LP, Li SS, Laws RJ et al. A common dominant TLR5 stop codon polymorphism abolishes flagellin signaling and is associated with susceptibility to legionnaires' disease. J Exp Med 2003; 198: 1563-1572.

23 Hawn TR, Scholes D, Li SS, Wang H, Yang Y, Roberts PL et al. Toll-like receptor polymorphisms and susceptibility to urinary tract infections in adult women. PLoS One 2009; 4: e5990.

24 Bochud PY, Hawn TR, Siddiqui MR, Saunderson P, Britton S, Abraham I et al. Toll-like receptor 2 (TLR2) polymorphisms are associated with reversal reaction in leprosy. J Infect Dis 2008; 197: 253-261.

25 Thuong NT, Hawn TR, Thwaites GE, Chau TT, Lan NT, Quy HT et al. A polymorphism in human TLR2 is associated with increased susceptibility to tuberculous meningitis. Genes Immun 2007; 8: 422-428.

26 Hawn TR, Misch EA, Dunstan SJ, Thwaites GE, Lan NT, Quy HT et al. A common human TLR1 polymorphism regulates the innate immune response to lipopeptides. Eur J Immunol 2007; 37: 2280-2289.

27 Barreiro LB, Neyrolles O, Babb CL, Tailleux L, Quach H, McElreavey $\mathrm{K}$ et al. Promoter variation in the DC-SIGNencoding gene CD209 is associated with tuberculosis. PLoS Med 2006; 3: e20.

28 Reich DE, Goldstein DB. Detecting association in a casecontrol study while correcting for population stratification. Genet Epidemiol 2001; 20: 4-16.

29 West TE, Hawn TR, Skerrett SJ. Toll-like receptor signaling in airborne Burkholderia thailandensis infection. Infect Immun 2009; 77: 5612-5622.

30 Barber RC, Chang LY, Arnoldo BD, Purdue GF, Hunt JL, Horton JW et al. Innate immunity SNPs are associated with risk for severe sepsis after burn injury. Clin Med Res 2006; 4: 250-255. 
31 Allen A, Obaro S, Bojang K, Awomoyi AA, Greenwood BM, Whittle $\mathrm{H}$ et al. Variation in Toll-like receptor 4 and susceptibility to group A meningococcal meningitis in Gambian children. Pediatr Infect Dis J 2003; 22: 1018-1019.

32 Cooke GS, Segal S, Hill AV. Toll-like receptor 4 polymorphisms and atherogenesis. N Engl J Med 2002; 347: 1978-1980; author reply 1978-80.

33 Faber J, Meyer CU, Gemmer C, Russo A, Finn A, Murdoch C et al. Human toll-like receptor 4 mutations are associated with susceptibility to invasive meningococcal disease in infancy. Pediatr Infect Dis J 2006; 25: 80-81.

34 Moens L, Verhaegen J, Pierik M, Vermeire S, De Boeck K, Peetermans WE et al. Toll-like receptor 2 and toll-like receptor 4 polymorphisms in invasive pneumococcal disease. Microbes Infect 2007; 9: 15-20.

35 Read RC, Pullin J, Gregory S, Borrow R, Kaczmarski EB, di Giovine FS et al. A functional polymorphism of toll-like receptor 4 is not associated with likelihood or severity of meningococcal disease. J Infect Dis 2001; 184: 640-642.

36 Hawn TR, Verbon A, Janer M, Zhao LP, Beutler B, Aderem A. Toll-like receptor 4 polymorphisms are associated with resistance to Legionnaires' disease. Proc Natl Acad Sci USA 2005; 102: 2487-2489.

37 Li Y, Chang M, Abar O, Garcia V, Rowland C, Catanese J et al. Multiple variants in toll-like receptor 4 gene modulate risk of liver fibrosis in Caucasians with chronic hepatitis $\mathrm{C}$ infection. J Hepatol 2009; 51: 750-757.
38 Chanchamroen S, Kewcharoenwong C, Susaengrat W, Ato M, Lertmemongkolchai G. Human polymorphonuclear neutrophil responses to Burkholderia pseudomallei in healthy and diabetic subjects. Infect Immun 2009; 77: 456-463.

39 Jagannathan M, McDonnell M, Liang Y, Hasturk H, Hetzel J, Rubin D et al. Toll-like receptors regulate B cell cytokine production in patients with diabetes. Diabetologia 2010; 53: 1461-1471.

40 Cheng AC, Peacock SJ, Limmathurotsakul D, Wongsuvan G, Chierakul W, Amornchai P et al. Prospective evaluation of a rapid immunochromogenic cassette test for the diagnosis of melioidosis in northeast Thailand. Trans $R$ Soc Trop Med Hyg 2006; 100: 64-67.

41 Dunstan SJ, Hawn TR, Hue NT, Parry CP, Ho VA, Vinh H et al. Host susceptibility and clinical outcomes in toll-like receptor 5-deficient patients with typhoid fever in Vietnam. J Infect Dis 2005; 191: 1068-1071.

42 Barrett JC, Fry B, Maller J, Daly MJ. Haploview: analysis and visualization of LD and haplotype maps. Bioinformatics 2005; 21: 263-265.

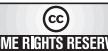

This work is licensed under the Creative Commons Attribution-NonCommercial-No Derivative Works 3.0 Unported License. To view a copy of this license, visit http://creativecommons.org/licenses/ by-nc-nd/3.0/

Supplementary Information accompanies the paper on Genes and Immunity website (http://www.nature.com/gene) 